\title{
Beth (Site et industries de l'oued), Maroc
}

\section{G. Souville}

\section{CpenEdition}

Journals

Édition électronique

URL : http://journals.openedition.org/encyclopedieberbere/1702

DOI : 10.4000/encyclopedieberbere.1702

ISSN : 2262-7197

\section{Éditeur}

Peeters Publishers

\section{Édition imprimée}

Date de publication : 1 décembre 1991

Pagination : 1480-1482

ISBN : 2-85744-549-0

ISSN : 1015-7344

\section{Référence électronique}

G. Souville, «Beth (Site et industries de l'oued), Maroc », Encyclopédie berbère [En ligne], 10 | 1991, document B69, mis en ligne le 01 mars 2013, consulté le 25 septembre 2020. URL : http:// journals.openedition.org/encyclopedieberbere/1702 ; DOI : https://doi.org/10.4000/ encyclopedieberbere. 1702

Ce document a été généré automatiquement le 25 septembre 2020.

(c) Tous droits réservés 


\title{
Beth (Site et industries de l'oued), Maroc
}

\author{
G. Souville
}

1 On peut distinguer à l'oued Beth proprement dit (carte au 1/50 000, Bataille, c.L. 450, $25 \times 365$ ) une "station néolithique » reconnue par A. Ruhlmann qu'il considère comme un véritable village en relation avec l'oppidum, une grotte, des abris sous roche et un éperon barré. Village, grottes et abris n'ont malheureusement pas été fouillés. Les importants travaux de reboisement rendront très difficiles des recherches ultérieures.

2 Le camp, situé sur une butte $(208 \mathrm{~m})$, est limité à l'est par une falaise rocheuse, à l'ouest par une arête dominant un vallon, au sud par un contrefort naturel. Le flanc ouest est renforcé par un mur de terre, long de $60 \mathrm{~m}$; l'escarpement rocheux du sud est souligné par un mur de pierres sèches. Au nord, où se trouvait le seul accès facile, un rempart coupe le promontoire d'ouest en est et mord même le versant oriental. Il mesurait $78 \mathrm{~m}$ de long, $5 \mathrm{~m}$ de haut, était large à la base de $7 \mathrm{~m}$ et de 2,5 à $3 \mathrm{~m}$ au sommet. A l'origine, ces dimensions, surtout la hauteur, devaient être plus importantes qu'au moment des relevés de Ruhlmann comme le montre un amoncellement de pierres sur toute la longueur du rempart. Celui-ci était construit en terre sans parement avec une assise de pierres brutes, sans mortier mais d'un assemblage assez régulier et mesurant environ 2 $\mathrm{m}$ de large. Une tranchée en pente douce le renforce vers l'intérieur, large de $50 \mathrm{~m}$ avec une profondeur maximale de $5 \mathrm{~m}$.

3 Un second rempart, à $85 \mathrm{~m}$ du premier, forme une nouvelle ligne de défense ; construit en terre surmontée de pierres sèches, il mesure $77 \mathrm{~m}$ de long. La place forte couvre une superficie de 2 ha ; elle était probablement en relation avec les camps voisins de Dchîra (à 2 km à vol d'oiseau) et d'Hälabädu (à 4,5km).

4 Dchîra et Hälabädu sont dans des positions comparables et présentent des dispositifs similaires. L'oppidum de Dchîra est également sur une position élevêe $(236 \mathrm{~m})$. Sur trois côtés, les protections naturelles sont renforcées par une enceinte de pierres sèches ; seule à l'ouest, une falaise à pic n'avait pas besoin de construction. Au nord-ouest un rempart barre le plateau, formé de terres rapportées couronnées par un mur de pierres 
sèches (longueur $55 \mathrm{~m}, 4$ à $5 \mathrm{~m}$ de large à la base). Comme à l'oued Beth, un réduit a été aménagé à l'intérieur, protégé par un mur de terre. L'ensemble du site couvre 3 ha.

Plan des sites de l'oued Beth. Dessin J. Lenne (d'après Bull. Soc Préhist. Maroc, 10, 1936, pl. I).

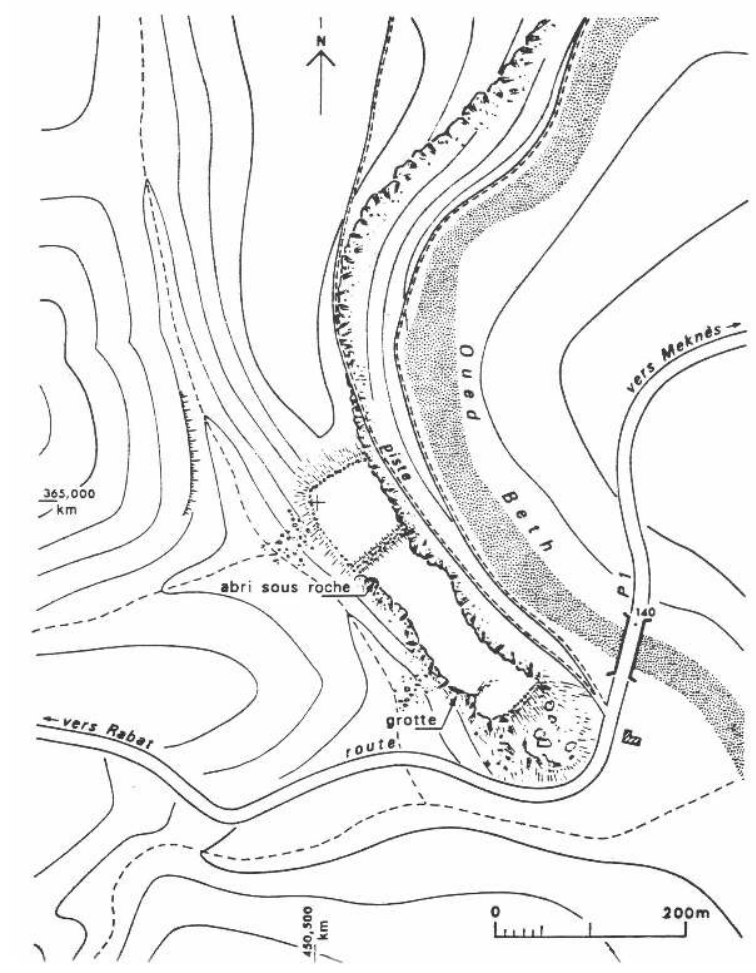

5 A Hālabādu, l'altitude est moins grande $(196 \mathrm{~m})$; le sommet de la colline est ceinturé par une enceinte en pierres brutes qui consolide les obstacles naturels. Le plateau est lui aussi barré par une levée de terre surmontée d'un mur en pierres sèches et mesurant $120 \mathrm{~m}$ de long.

6 A l'intérieur ou à proximité de ces camps fut recueillie une très abondante industrie représentée notamment par des pierres à cupules et à rainures, une cinquantaine de meules dormantes, plus de cent cinquante broyeurs et molettes, cent quatre-vingts pilons. Deux éléments sont particulièrement notables : la présence de pièces à gorge et l'abondance des haches. Celles-ci bouchardées avec des parties plus ou moins polies, parfois fragmentaires dépassent le nombre de neuf cents.

7 Quant aux pièces à gorge, elles sont très caractéristiques de cette région; on peut dénombrer une cinquantaine d'outils, généralement allongés (ovoïdes, cylindriques) avec une gorge plus ou moins marquée, éventuellement soulignée par un bourrelet ou deux renflements ; la gorge peut être double et même être accompagnée d'une rainure perpendiculaire (Souville G., « Les différents éléments de l'industrie en pierre polie du Maghreb ", Actes Congr. panafricain Préhist. et Et. Quaternaire, $7^{e}$ session, Addis Ababa, 1971 (1976), pp. 197-204).

8 Cette industrie accompagnée de tessons de céramique laisse supposer un début d'agriculture, du moins du broyage et la consommation de graines et de céréales. Si certaines pièces à gorge ont pu être des pics de mineur, d'autres ont dû servir d'instruments aratoires. Installations et industries peuvent appartenir à un néolithique récent (Bensimon Y. et Martineau M., «Le Néolithique marocain en 1986 », 
L'Anthropologie, t. 91, 1987, pp. 631-632) et à un faciès régional, voire aux civilisations protohistoriques.

\section{BIBLIOGRAPHIE}

RUhlmann A., « Le Ténéréen », Bull. Soc. Préhist. Maroc, t. 10, 1936, pp. 3-15 (et Congr. préhist. France, C.-R. $12^{\mathrm{e}}$ session, Toulouse-Foix, 1936 (1937), pp. 801-812, même texte).

Id., « Enceintes préhistoriques marocaines », Bull. Soc,. Préhist. Maroc, t. 10, 1936, pp. 41-67.

SOUVILLE G., Atlas préhistorique du Maroc, 1, Le Maroc atlantique, Paris, 1973, pp. 148-163.

Id., « Les sites de l'oued Beth (Maroc) : exploitation rurale et protection militaire ", Bull, archéol. Comité Trav. hist. et sci., n.s., t. 17 B, 1981, pp. 237-240.

воквот Ү., Habitats et monuments funéraires au Maroc protohistorique, Aix-en-Provence, 1991, thèse de doctorat multigraphiée.

INDEX

Mots-clés : Maroc, Préhistoire, Protohistoire 